\title{
EFFECT OF ACUTELY INCREASED LEFT VENTRICULAR AFTERLOAD ON WORK OUTPUT FROM THE RIGHT VENTRICLE IN CONSCIOUS DOGS
}

Mohanraj K. Karunanithi, BE, MBiomedE

Jerzy Michniewicz, MBBS, MBA

Jason A. Young, BE, MBiomedE

Michael P. Feneley, MD, FACC
Objective: To determine the effect of acute increments in left ventricular afterload on the stroke work output of the right ventricle in vivo.

Methods: After pharmacologic attenuation of autonomic reflexes, left and right ventricular pressure-volume data were obtained in 9 conscious dogs during vena caval occlusions performed before and during aortic constriction.

Results: The relationship between right ventricular stroke work and enddiastolic volume during vena caval occlusion was highly linear $(r=0.97 \pm$ 0.02 ), but the slope decreased by $20 \% \pm 13 \%$ during aortic constriction sufficient to increase left ventricular mean ejection pressure by $25 \% \pm 14 \%$ $(P<.05)$. The volume-axis intercept remained constant. Similarly, the slope of the linear relationship between right ventricular free wall regional segment work and end-diastolic segment length declined by $22 \% \pm 10 \%$ during aortic constriction $(P<.05)$, without significant change in the length-axis intercept. The reduction in both global and regional right ventricular stroke work at any given preload with increased left ventricular afterload was due entirely to decreased right ventricular stroke volume and free wall shortening, because right ventricular mean ejection pressure was unchanged. Additional experiments were performed in 5 open-chest dogs to produce a greater reduction in left ventricular free wall shortening than observed with aortic constriction by transient constriction of the left circumflex coronary artery. However, this intervention had no effect on right ventricular free wall segment work output.

Conclusion: Increased left ventricular afterload decreases global and regional right ventricular stroke work at any given preload, a direct, negative systolic ventricular interaction. (J Thorac Cardiovasc Surg 2001;121:116-24) nteractions between the left ventricle (LV) and the right ventricle (RV) during diastole are well characterized: increased filling of either ventricle displaces the interventricular septum toward the opposite ventricle,

From The Victor Chang Cardiac Research Institute and Cardiology Department, St Vincent's Hospital, Sydney, Australia.

Supported by a Project Grant from the National Health and Medical Research Council of Australia.

Received for publication Jan 18, 2000; revisions requested March 14, 2000; revisions received May 1, 2000; accepted for publication Aug 7, 2000.

Address for reprints: Michael P. Feneley, MD, FRACP, FACC, Cardiology Department, St Vincent's Hospital, Darlinghurst, NSW 2010, Australia (E-mail: M.Karunanithi@unsw.edu.au).

Copyright (C) 2001 by The American Association for Thoracic Surgery

0022-5223/2001 $\$ 35.00+0 \quad \mathbf{1 2 / 1 / 1 1 0 6 8 3}$

doi:10.1067/mtc.2001.110683 thereby decreasing the latter's diastolic compliance, ${ }^{1-4}$ an effect enhanced by the intact pericardium. ${ }^{3,5,6}$ Systolic ventricular interactions are less well characterized $^{7}$ but are of potential significance to the design and operation of ventricular assist devices. ${ }^{8}$ There is considerable evidence that $\mathrm{LV}$ contraction contributes to RV systolic function, ${ }^{9-13}$ but the mechanism of this interaction remains speculative.

Feneley and colleagues ${ }^{14}$ demonstrated previously that acute increments in RV afterload increase the work output from the LV at any given end-diastolic volume (preload), a direct, positive systolic ventricular interaction. Leftward systolic displacement of the interventricular septum due to the increase in RV systolic pressure during increased RV afterload contributes to this interaction. ${ }^{14}$

In this study, we tested the converse hypothesis that acute increments in LV afterload would increase RV 

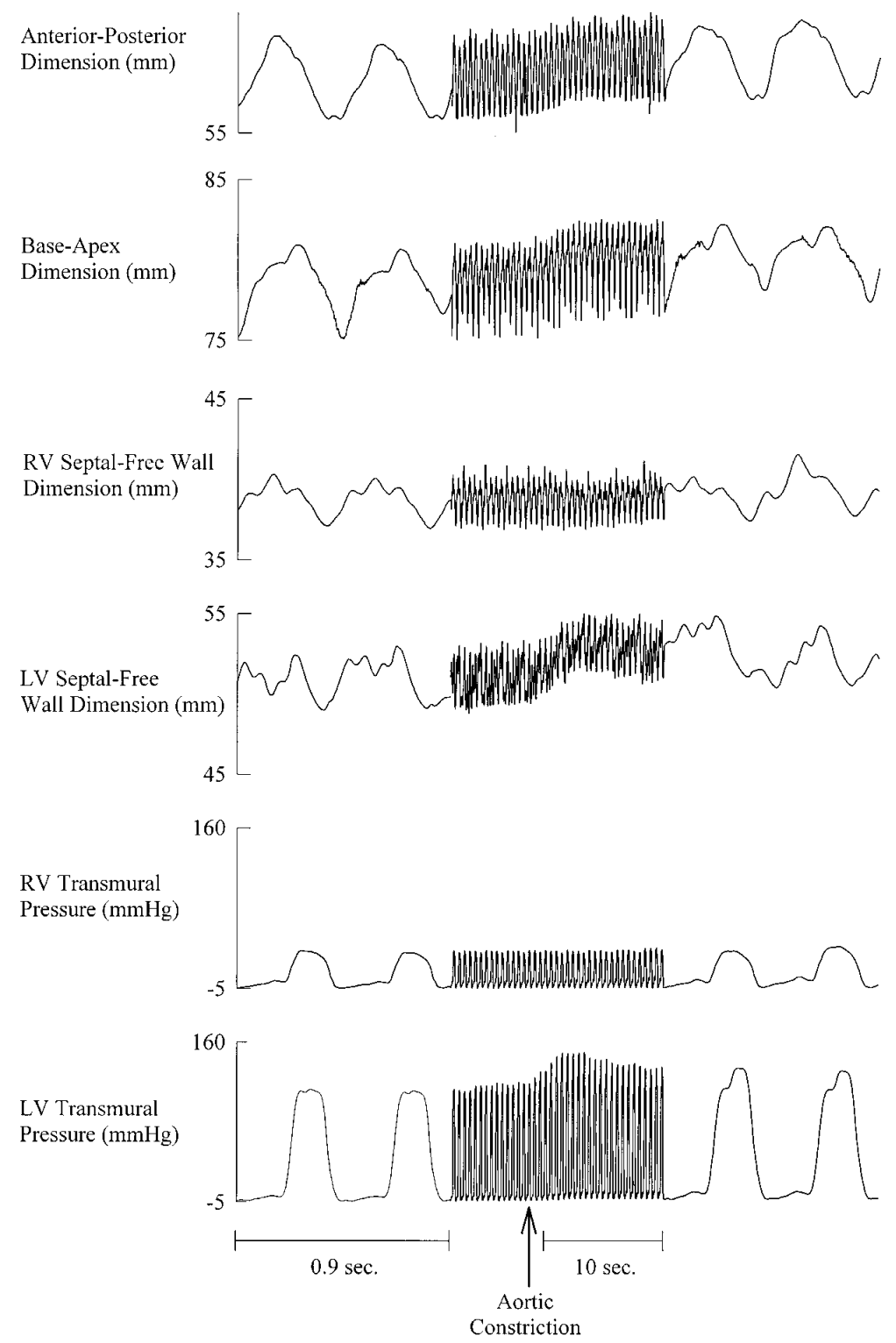

Fig 1. Representative cardiac dimensions and pressures recorded under control conditions and during aortic constriction.

stroke work at any given preload. Because the two ventricles are connected in series via the pulmonary and systemic circulations, alterations in LV afterload might influence RV work output by altering RV end-diastolic volume (preload). ${ }^{15}$ To examine the direct ventricular interactive effect of increased LV afterload on RV work output, therefore, we performed transient vena caval occlusions to cause wide variations in RV end-diastolic volume before and during aortic constriction. This experimental approach allowed us to express RV stroke work as a linear function of RV end-diastolic volume ${ }^{16}$ before and during increased LV afterload, thereby accounting for any in-series effects on preload. ${ }^{15} \mathrm{We}$ found that increased LV afterload decreased RV stroke work at any given end-diastolic volume: a direct, negative systolic ventricular interaction.

\section{Materials and methods}

The experiments described herein were approved by our institutional ethics committee and conformed to the guidelines of the National Health and Medical Research Council of Australia. 

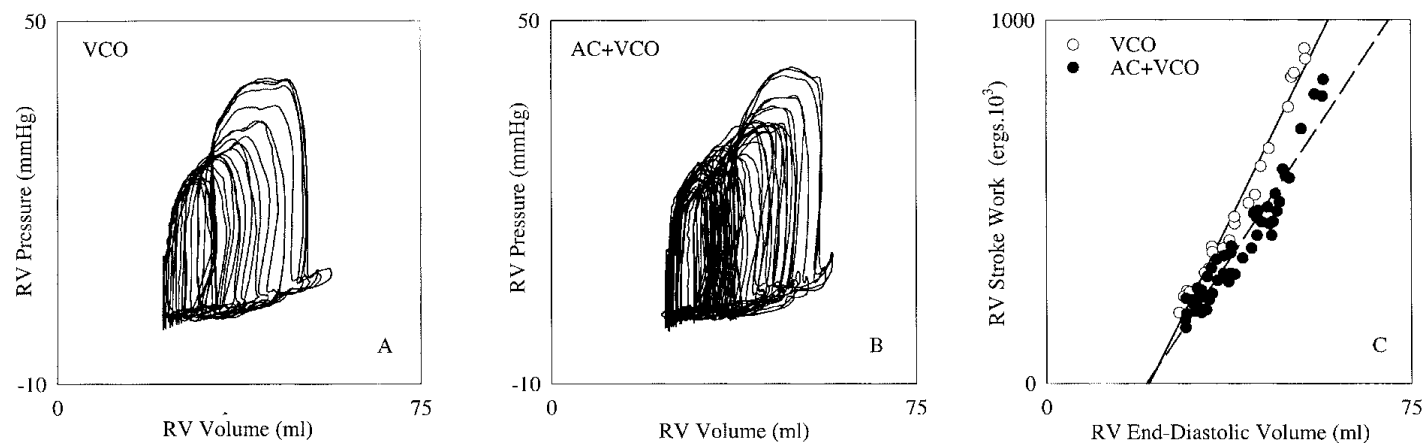

Fig 2. RV pressure-volume loops recorded during vena caval occlusions before (panel $\mathbf{A}, V C O$ ) and during aortic constriction (panel $\mathbf{B}, A C+V C O$ ), together with the corresponding RV stroke work-end-diastolic volume relationships derived from these loops (panel $\mathbf{C}$ ).
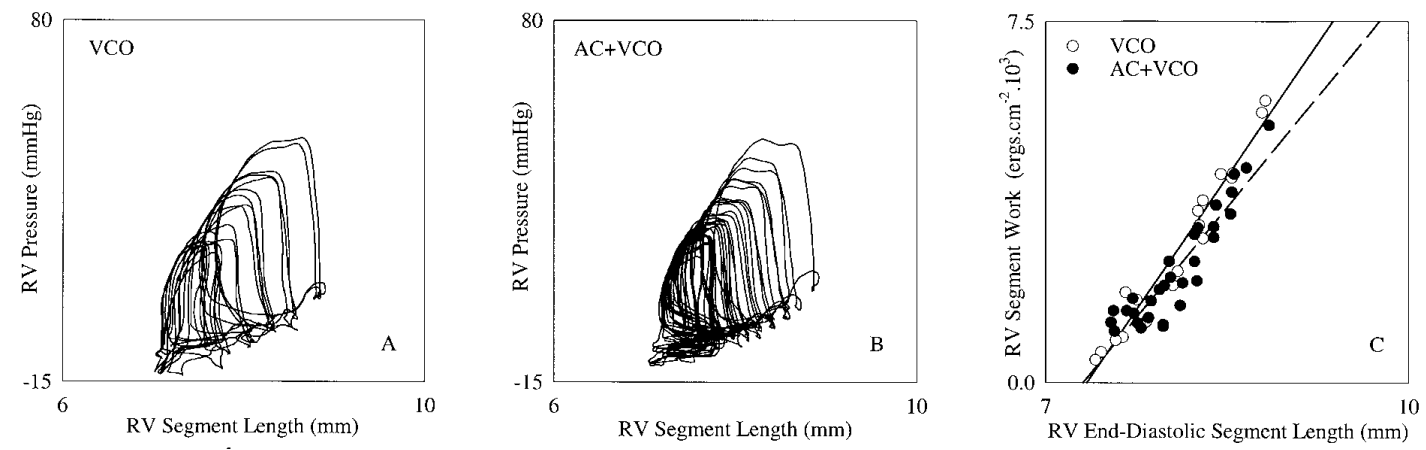

Fig 3. RV free wall regional pressure-segment length loops recorded during vena caval occlusions before (panel $\mathbf{A}, V C O$ ) and during aortic constriction (panel $\mathbf{B}, A C+V C O$ ), together with the corresponding RV regional segment work-end-diastolic segment length relationships derived from those loops (panel $\mathbf{C}$ ).

\section{Experiment 1}

Experimental preparation. Nine healthy adult dogs (22$42 \mathrm{~kg}$ ) were anesthetized (halothane $1 \%-2 \%$ and succinylcholine $0.3 \mathrm{mg} \cdot \mathrm{kg}^{-1}$ intravenously [iv] after thiamylal sodium $20 \mathrm{mg} \cdot \mathrm{kg}^{-1} \mathrm{iv}$ ). Through a left thoracotomy, pulsetransit ultrasonic dimension transducers were positioned across the base-apex (a) and anteroposterior (b) axes of the LV and across the septal-free wall axes of the LV (c) and RV (d) ${ }^{14,16,17}$ An additional pair of transducers was positioned to measure a regional segment length on the RV mid-free wall, perpendicular to the major axis. ${ }^{17}$ Pneumatic occluders were positioned around the inferior vena cava and the descending thoracic aorta. Heparin-filled silicone catheters $(2.6 \mathrm{~mm}$ in inner diameter) were secured in the base of the left atrial appendage and the apex of the RV. Another catheter with multiple side holes was positioned adjacent to the ventricular epicardium. Because surgical closure of the pericardium over the various devices on the surface of the heart was expected to produce an unphysiologic degree of pericardial constraint, the pericardium was left wide open, and the thoracotomy was repaired. After 7 to 10 days, the transducer leads, catheters, and occluder tubing were exteriorized from a subcutaneous pouch. Each animal, lying quietly on its right side, was studied in the conscious state 1 hour after light sedation (morphine sulfate, $10 \mathrm{mg}$ intramuscularly).

Data acquisition and experimental protocol. Micromanometer-tipped catheters (model MPC-500; Millar Instruments, Inc, Houston, Tex) were passed via the implanted catheters to obtain RV, LV, and pleural pressures. Autonomic reflexes were attenuated with intravenous propranolol $\left(1 \mathrm{mg} \cdot \mathrm{kg}^{-1}\right)$ and atropine $\left(0.2 \mathrm{mg} \cdot \mathrm{kg}^{-1}\right)$. Data were recorded under steady-state conditions and during transient vena caval occlusion induced by inflation of the implanted occluder for approximately 10 seconds. After return of all variables to their baseline levels, the descending aortic occluder was inflated sufficiently to achieve a stable increment in LV systolic pressure of approximately $30 \%$. After a 60 -second wait to ensure stabilization of all variables at their new levels, thereby excluding any transient effects of increased afterload on LV contractile function, ${ }^{18}$ transient vena caval occlusion was repeated while the aortic constriction was maintained.

\section{Experiment 2}

Experimental preparation. We examined the direct influence of reduced LV free wall shortening on RV free wall 


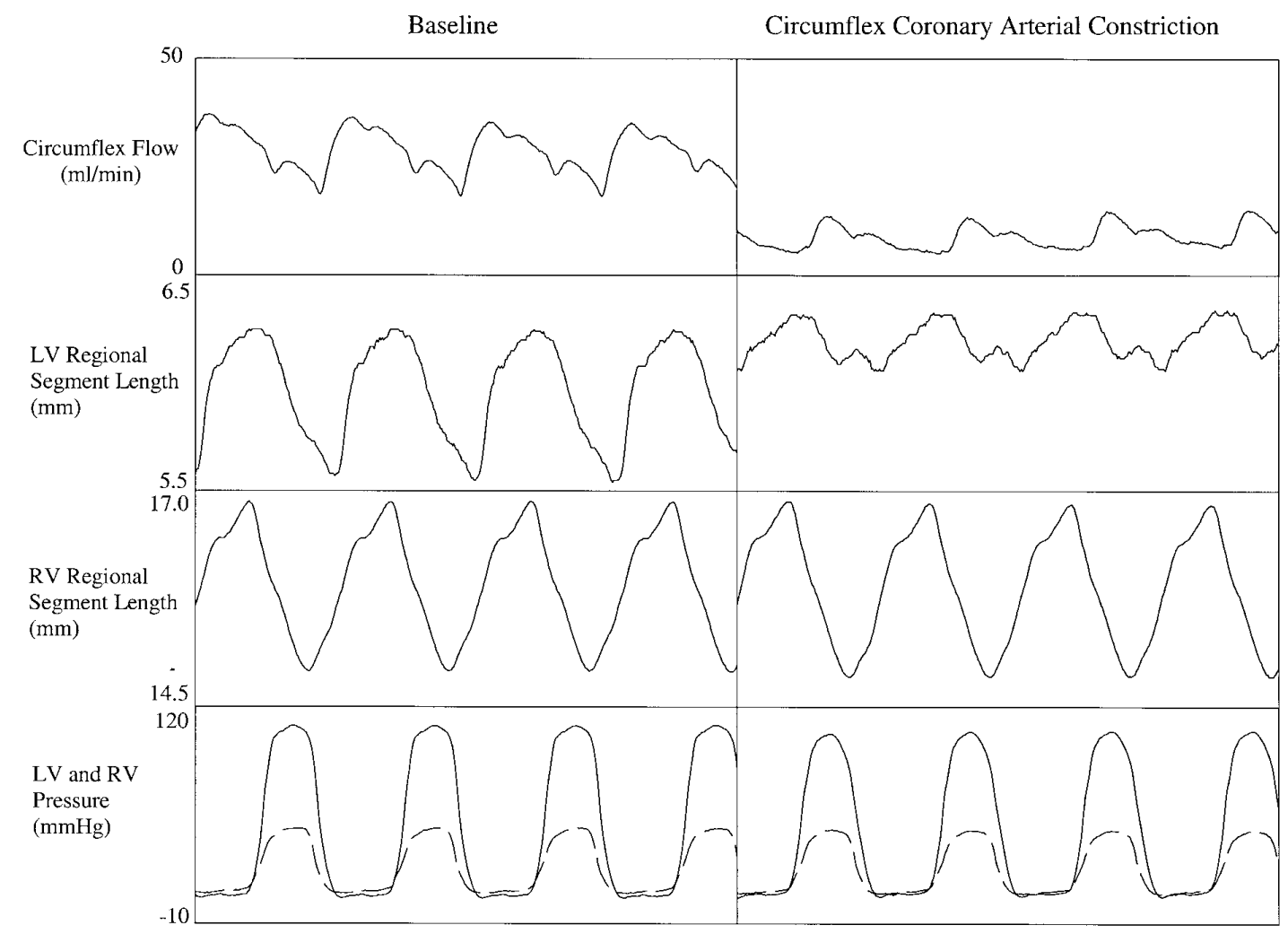

Fig 4. Representative dynamic waveforms demonstrating reduction of LV free wall segment shortening with constriction of circumflex coronary artery flow, but no significant change in RV free wall segment shortening or pressure.

function in separate open-chest experiments. Five healthy adult dogs $(29-40 \mathrm{~kg}$ ) were anesthetized (fentanyl $0.05 \mu \mathrm{g}$. $\mathrm{kg}^{-1} \cdot \mathrm{min}^{-1}$ iv and halothane $0.5 \%$ after thiopenthal sodium $\left.20 \mathrm{mg} \cdot \mathrm{kg}^{-1} \mathrm{iv}\right)$. Through a left thoracotomy, a pair of ultrasonic transducers was positioned to measure lateral LV free wall segment shortening in the distribution of the largest ventricular branch of the circumflex coronary artery. The transducers were positioned parallel to the minor-axis plane of the LV. A similar pair of transducers was positioned directly opposite to measure RV free wall segment shortening, as described for experiment 1. A polyester tape was placed around the main circumflex coronary artery to permit controlled reduction in blood flow, which was measured with a flow probe (Transonic Systems Inc, Ithaca, NY). Pneumatic occluders were positioned around the inferior vena cava and the descending thoracic aorta. LV and RV pressures were measured with micromanometers (Millar model MPC-500) introduced through the apex.

Data acquisition and experimental protocol. The same sequence of vena caval and aortic constrictions after pharmacologic attenuation of autonomic reflexes described for experiment 1 was performed. This sequence was then repeated during constriction of the circumflex coronary artery suf- ficient to achieve approximately $50 \%$ reduction in $\mathrm{LV}$ free wall segmental shortening.

Data analysis. Data were digitized in real time at $200 \mathrm{~Hz}$. LV chamber volume was calculated from the ultrasonic dimension measurements according to the formula for a general ellipsoid $\left(\pi / 6 a \cdot b^{2}-L V\right.$ wall volume) ${ }^{19} \mathrm{RV}$ chamber volume was calculated according to an ellipsoidal shell subtraction model $(\pi / 6 \mathrm{a} \cdot \mathrm{b} \cdot \mathrm{d}-\mathrm{RV}$ free wall volume $){ }^{17}$ Postmortem wall volumes were determined by water displacement. LV and RV transmural pressures were calculated as chamber pressures minus pleural pressure. End-systolic pressure was defined at the time when the instantaneous pressure-volume ratio was maximal. The end-systolic pressurevolume relationship (ESPVR) of each ventricle was determined by linear regression analysis. ${ }^{20}$

Stroke work for each ventricle was calculated as the pressure-volume loop area for each beat. LV or RV free wall regional segment work was calculated as the pressure-dimension loop area for each beat. Global preload recruitable stroke work (PRSW) relationships between stroke work and enddiastolic volume and regional PRSW relationships between regional segment work and end-diastolic segment length during each vena caval occlusion were determined by linear regression analyses. ${ }^{16,17,19}$ 
Table I. Baseline RV hemodynamic and cardiac dimension data

\begin{tabular}{|c|c|c|c|c|c|c|c|}
\hline & $\begin{array}{c}H R \\
\text { (beats/min) }\end{array}$ & $\begin{array}{l}E D V \\
(m L)\end{array}$ & $\begin{array}{c}S V \\
(m L)\end{array}$ & $\begin{array}{c}M E P \\
(m m H g)\end{array}$ & $\begin{array}{c}S W \\
\left(\operatorname{erg} \cdot 10^{3}\right)\end{array}$ & $\begin{array}{c}R S W \\
\left(\mathrm{erg} \cdot 10^{3} \cdot \mathrm{cm}^{-2}\right)\end{array}$ & $\begin{array}{l}L_{e d} \\
(\mathrm{~cm})\end{array}$ \\
\hline Control $($ mean $\pm \mathrm{SD})$ & $132 \pm 15$ & $47.5 \pm 23.4$ & $14.2 \pm 6.0$ & $32.4 \pm 5.9$ & $560 \pm 245$ & $2.5 \pm 2.9$ & $1.16 \pm 0.54$ \\
\hline Aortic constriction (mean $\pm \mathrm{SD})$ & $128 \pm 15^{*}$ & $48.0 \pm 24.4$ & $11.6 \pm 7.1^{*}$ & $33.0 \pm 7.6$ & $457 \pm 270^{*}$ & $1.9 \pm 3.0^{*}$ & $1.16 \pm 0.52$ \\
\hline
\end{tabular}

$H R$, Heart rate; $E D V$, end-diastolic volume; $S V$, stroke volume; $M E P$, mean ejection pressure; $S W$, global stroke work; $R S W$, free wall regional segment work; $L$, free wall segment length; $a$, base-apex dimension; $b$, anteroposterior dimension; $c$, left ventricular septal-free wall dimension; $d$, right ventricular septal-free wall dimension; $e d$, end-diastole; $\Delta$, systolic shortening.

$* P<.05$ versus control.

Table II. $R$ V linear regression data

\begin{tabular}{|c|c|c|c|c|}
\hline \multirow[b]{2}{*}{ Ordinate } & \multirow[b]{2}{*}{ Abscissa } & \multicolumn{3}{|c|}{ Control } \\
\hline & & Slope & $x$-Intercept & $r$ \\
\hline SW & EDV & $23.9 \pm 8.9\left(\mathrm{erg} \cdot 10^{3} \cdot \mathrm{mL}^{-1}\right)$ & $25.3 \pm 8.9(\mathrm{~mL})$ & $0.97 \pm 0.02$ \\
\hline MEP & EDV & $0.79 \pm 0.34\left(\mathrm{~mm} \mathrm{Hg} \cdot \mathrm{mL}^{-1}\right)$ & $1.68 \pm 32.7(\mathrm{~mL})$ & $0.97 \pm 0.01$ \\
\hline SV & EDV & $0.41 \pm 0.17\left(\mathrm{~mL} \cdot \mathrm{mL}^{-1}\right)$ & $6.87 \pm 9.42(\mathrm{~mL})$ & $0.90 \pm 0.09$ \\
\hline RSW & $\mathrm{L}_{\mathrm{ed}}$ & $56.2 \pm 41.1\left(\mathrm{erg} \cdot 10^{3} \cdot \mathrm{cm}^{-3}\right)$ & $9.0 \pm 1.9(\mathrm{~mm})$ & $0.84 \pm 0.24$ \\
\hline ESP & ESV & $1.3 \pm 0.6\left(\mathrm{~mm} \mathrm{Hg} \cdot \mathrm{mL}^{-1}\right)$ & $11.5 \pm 18.0(\mathrm{~mL})$ & $0.96 \pm 0.03$ \\
\hline
\end{tabular}

$E S P$, End-systolic pressure; ESV, end-systolic volume. Other abbreviations as for Table I.

$* P<.05$ versus control.

Table III. Calculation of the contribution of reduced $R V$ septal-free wall shortening to reduced steady-state $R V$ stroke work with increased LV afterload

\begin{tabular}{|c|c|c|c|c|}
\hline & \multirow[b]{2}{*}{$\begin{array}{c}\text { Control } \\
\left(\mathrm{erg} \cdot 10^{3}\right)\end{array}$} & \multicolumn{2}{|c|}{ Aortic constriction } & \multirow[b]{2}{*}{$\begin{array}{l}\text { Difference in stroke } \\
\text { work reduction (\%) }\end{array}$} \\
\hline & & $\begin{array}{l}\text { Observed } \\
\left(\mathrm{erg} \cdot 10^{3}\right)\end{array}$ & $\begin{array}{c}\text { Calculated }^{*} \\
\left(\mathrm{erg} \cdot 10^{3}\right)\end{array}$ & \\
\hline Stroke work & $532 \pm 267$ & $388 \pm 236$ & $431 \pm 240$ & $34 \pm 23$ \\
\hline
\end{tabular}

Results are summarized as mean \pm SD. Multiple comparisons were performed by analysis of variance. Paired comparisons were made with paired $t$ tests. The effects of increased LV afterload on the ESPVR and PRSW relationships were determined by multiple linear regression analyses. ${ }^{20}$

\section{Results}

Experiment 1. Representative dynamic data recordings obtained under control conditions and during aortic constriction are shown in Fig 1. Mean baseline data are presented in Table I. RV pressure-volume loops obtained during runs of vena caval occlusion before and during aortic constriction are shown in Fig 2, $A$ and $\mathrm{B}$, together with the corresponding RV PRSW relationships (Fig 2, C). The mean linear regression data are presented in Table II.

Aortic constriction increased LV mean ejection pressure from $118 \pm 17 \mathrm{~mm} \mathrm{Hg}$ to $146 \pm 13 \mathrm{~mm} \mathrm{Hg}(25 \%$ $\pm 14 \%)$, increased LV end-diastolic volume $(24 \% \pm$
$39 \%)$, and decreased LV stroke volume $(17 \% \pm 20 \%)$. Increased LV afterload did not significantly change RV end-diastolic volume or RV mean ejection pressure, but RV stroke volume decreased $22 \% \pm 21 \%$, and RV stroke work decreased $19 \% \pm 19 \%$. Similarly, RV free wall segment shortening decreased $19 \% \pm 18 \%$ without significant change in end-diastolic segment length.

The RV PRSW relationship was highly linear (Table II), as was the LV PRSW relationship ( $r=0.93 \pm 0.12)$. During aortic constriction, the slope of the RV PRSW relationship decreased $20 \% \pm 13 \%$ without significant change in the volume-axis intercept (Fig 2). That is, an acute increase in LV afterload decreased RV stroke work at any given end-diastolic volume. This reduction in RV stroke work was due to the reduction in RV stroke volume because there was no significant reduction in RV mean ejection pressure for any given end-diastolic volume (Table II). The slope of the LV PRSW relationship 


\begin{tabular}{|c|c|c|c|c|c|c|c|c|}
\hline $\begin{array}{c}\Delta L \\
(\mathrm{~cm})\end{array}$ & $\begin{array}{l}a_{e d} \\
(\mathrm{~cm})\end{array}$ & $\begin{array}{l}\Delta a \\
(\%)\end{array}$ & $\begin{array}{l}b_{e d} \\
(\mathrm{~cm})\end{array}$ & $\begin{array}{l}\Delta b \\
(\%)\end{array}$ & $\begin{array}{l}C_{e d} \\
(\mathrm{~cm})\end{array}$ & $\begin{array}{l}\Delta c \\
(\%)\end{array}$ & $\begin{array}{l}d_{e d} \\
(\mathrm{~cm})\end{array}$ & $\begin{array}{l}\Delta d \\
(\%)\end{array}$ \\
\hline $0.08 \pm 0.04$ & $8.18 \pm 0.58$ & $2.79 \pm 1.50$ & $6.12 \pm 0.37$ & $6.57 \pm 1.03$ & $5.39 \pm 0.64$ & $6.30 \pm 2.05$ & $3.49 \pm 0.81$ & $7.04 \pm 6.76$ \\
\hline $0.06 \pm 0.04 *$ & $8.28 \pm 0.60^{*}$ & $1.92 \pm 1.36^{*}$ & $6.22 \pm 0.34 *$ & $5.32 \pm 1.28^{*}$ & $5.60 \pm 0.80^{*}$ & $4.53 \pm 1.24^{*}$ & $3.40 \pm 0.86$ & $6.45 \pm 7.33^{*}$ \\
\hline
\end{tabular}

\begin{tabular}{ccc}
\hline & Aortic constriction & $r$ \\
\hline Slope & $x$-Intercept & $0.92 \pm 0.05$ \\
$19.4 \pm 9.3^{*}\left(\mathrm{erg} \cdot 10^{3} \cdot \mathrm{mL}^{-1}\right)$ & $24.8 \pm 12.2(\mathrm{~mL})$ & $0.95 \pm 0.02$ \\
$0.77 \pm 0.33\left(\mathrm{~mm} \mathrm{Hg} \cdot \mathrm{mL}^{-1}\right)$ & $3.85 \pm 30.37(\mathrm{~mL})$ & $0.70 \pm 0.22$ \\
$0.24 \pm 0.22^{*}\left(\mathrm{~mL} \cdot \mathrm{mL}^{-1}\right)$ & $18.1 \pm 74.7(\mathrm{~mL})$ & $0.75 \pm 0.28$ \\
$44.4 \pm 32.8^{*}\left(\mathrm{erg} \cdot 10^{3} \cdot \mathrm{cm}^{-3}\right)$ & $9.0 \pm 2.0(\mathrm{~mm})$ & $0.94 \pm 0.07$ \\
$1.2 \pm 0.4^{*}\left(\mathrm{~mm} \mathrm{Hg} \cdot \mathrm{mL}^{-1}\right)$ & $13.3 \pm 19.6(\mathrm{~mL})$ & \\
\hline
\end{tabular}

$\left(78.0 \pm 13.0 \mathrm{erg} \cdot 10^{3} \cdot \mathrm{mL}^{-1}\right)$ decreased slightly with increased LV afterload $\left(71.4 \pm 21.7 \mathrm{erg} \cdot 10^{3} \cdot \mathrm{mL}^{-1}\right)$ without significant change in the volume-axis intercept $(7.3 \pm$ $11.3 \mathrm{~mL}$ and $1.1 \pm 14.6 \mathrm{~mL}$, respectively).

$\mathrm{RV}$ free wall regional pressure-segment length loops obtained during runs of vena caval occlusion before and during aortic constriction are shown in Fig 3, $A$ and $B$, together with the corresponding RV regional PRSW relationships (Fig 3,C). The results of the regional work analysis mirror those of the global work analysis (Table II). Increased LV afterload decreased the slope of the RV regional PRSW relationship $22 \% \pm 10 \%$, without significantly changing the length-axis intercept.

The slope of the RV ESPVR decreased during aortic constriction without significant change in the volumeaxis intercept (Table II). The LV ESPVR shifted leftward significantly with increased LV afterload (the volumeaxis intercept decreased from $-13.1 \pm 15.6 \mathrm{~mL}$ to -32.9 $\pm 16.5 \mathrm{~mL})$ with a reduction in the slope $(2.7 \pm 1.1 \mathrm{~mm}$ $\mathrm{Hg} \cdot \mathrm{mL}^{-1}$ and $2.1 \pm 0.6 \mathrm{~mm} \mathrm{Hg} \cdot \mathrm{mL}^{-1}$, respectively).

Increased LV afterload was associated with a significant increase in all $3 \mathrm{LV}$ end-diastolic dimensions, but the RV septal-free wall dimension at enddiastole did not change significantly (Table I). The reduction in RV stroke volume during increased LV afterload was associated with a significant reduction in shortening of all $3 \mathrm{LV}$ dimensions and the RV septal-free wall dimension. For each of the dogs studied, we computed the steady-state RV stroke work that would have been generated if shortening of the RV septal-free wall dimension had remained unaltered by the increase in LV afterload (Table III), so that the reduction in RV stroke work was due only to the reduction in shortening of the base-apex and anteroposterior dimensions. This analysis indicated that the reduction in shortening of the RV septal-free wall dimension accounted for $34 \%$ of the observed reduction in RV stroke work, on average.

Experiment 2. Representative data from this experiment are shown in Fig 4. Mean results are summarized in Table IV. Ischemia sufficient to reduce LV free wall segmental shortening 50\% $\pm 37 \%$ did not significantly alter RV free wall shortening, RV mean ejection pressure, or RV segmental work. Furthermore, impaired LV free wall shortening had no significant effect on the RV regional PRSW relationship either under normal LV loading conditions or with aortic constriction, which increased LV mean ejection pressure from $105 \pm 16$ $\mathrm{mm} \mathrm{Hg}$ to $120 \pm 18 \mathrm{~mm} \mathrm{Hg}$.

\section{Discussion}

The major finding of this study is that the RV response to increased LV afterload is opposite to the $\mathrm{LV}$ response to increased RV afterload. Although an acute increase in RV afterload has been shown previously to increase LV stroke work at any given preload, ${ }^{14}$ this study demonstrates that an acute increase in $\mathrm{LV}$ afterload decreases both global and regional RV stroke work at any given preload: a direct, negative sys- 
Table IV. Steady-state hemodynamic and linear regression data before and after circumflex coronary arterial constriction

\begin{tabular}{lccccc}
\hline & & \multicolumn{3}{c}{$L V$} \\
\cline { 3 - 6 } & & & & & \\
& & & & & \\
& & & & \\
& $(\mathrm{mL} / \mathrm{min})$ & $(\mathrm{cm})$ & $(\%)$ & $(\mathrm{mm} \mathrm{Hg})$ & $\left(\mathrm{erg} \cdot 10^{3} \cdot \mathrm{cm}^{-2}\right)$ \\
\hline Control (mean $\pm \mathrm{SD})$ & $95 \pm 74$ & $8.6 \pm 3.0$ & $6.4 \pm 3.6$ & $102 \pm 18$ & $6.9 \pm 3.1$ \\
Circumflex constriction (mean $\pm \mathrm{SD})$ & $34 \pm 31^{*}$ & $8.7 \pm 2.9$ & $2.6 \pm 2.8^{*}$ & $99 \pm 17$ & $3.8 \pm 3.2^{*}$ \\
\hline
\end{tabular}

Abbreviations as in Table I.

$* P<.05$ versus control.

tolic ventricular interaction. This is the first report of such an interaction.

Three mechanisms of systolic ventricular interaction have been proposed. First, contraction of either ventricle may displace the interventricular septum toward the opposite ventricle. ${ }^{21-24}$ Second, the attachment of the $\mathrm{RV}$ free wall to the LV may permit RV chamber compression by LV contraction, analogous to the action of a bellows. ${ }^{25}$ Third, because common muscle fiber pathways encircle both ventricular free walls and others cross through the septum, forming a figure-of- 8 pattern, ${ }^{26}$ contraction of either ventricle might exert force on the opposite ventricular chamber by axial transmission along these common pathways.

The septal interaction mechanism is operative under conditions of both RV volume and RV pressure overload. ${ }^{21-24}$ The leftward diastolic septal displacement due to RV volume overload is reversed during early systole, resulting in paradoxic systolic motion of the septum into the RV. ${ }^{21}$ Conversely, leftward systolic septal displacement is a hallmark of RV pressure overload, reflecting the reduced left-to-right systolic transseptal pressure gradient due to the increased RV systolic pressure. ${ }^{14,22-24}$ This mechanism contributes to increased LV stroke work and systolic pressure with increased RV afterload ${ }^{14,27}$ and the leftward shift of the LV ESPVR with increased RV volume. , $^{5,28}$

The reduction in RV stroke work with increased LV afterload in this study, however, cannot be attributed to a septal mechanism. Shortening of the LV septal-free wall dimension and leftward systolic motion of the septum were impeded by increased LV afterload (Table I). Consequently, the reduced shortening of the RV septal-free wall dimension with increased LV afterload was due entirely to reduced shortening of the RV free wall toward the septum rather than increased motion of the septum away from the free wall.

The fact that increased LV afterload impeded RV free wall fiber shortening might suggest that RV free wall muscle fibers share some of the load "seen" by LV muscle fibers during contraction. Santamore and colleague ${ }^{29}$ demonstrated that incision or ischemia of the LV free wall in the isolated heart caused an immediate fall in RV isovolumic pressure, but these interventions also reduced LV pressure generation. In contrast, we observed no significant reduction in RV free wall shortening, stroke volume, mean ejection pressure, or regional stroke work during an ischemic reduction in regional LV shortening that caused no significant change in LV pressure generation. This finding suggests that the more modest reduction in LV fiber shortening observed with increased LV afterload cannot account directly for the reduction in RV free wall fiber shortening, thus discounting a role for the common fiber pathway mechanism of ventricular interaction.

The more probable explanation is altered RV free wall geometry during increased LV afterload. The increased anteroposterior and base-apex end-diastolic dimensions but unchanged RV free wall end-diastolic fiber length during increased LV afterload imply a flatter RV free wall, as demonstrated by Yamaguchi and colleagues ${ }^{30}$ by increasing LV volume relative to RV volume. The increased radius of RV free wall curvature would result in greater systolic stress for the same developed pressure, with a consequent reduction in systolic shortening.

Because septal curvature toward the RV is near maximal under normal loading conditions, ${ }^{14}$ the increment in the transseptal pressure gradient caused by increased LV afterload can cause little increase in septal curvature. The septum is more sensitive to leftward displacement by increased RV afterload because this displacement is associated with a reduction in septal curvature: septal compliance varies with septal position (see Fig 6 of reference 14). This also may explain the absence of a reduction in RV end-diastolic volume or RV enddiastolic septal-free wall dimension with increased LV afterload, particularly in the absence of an intact pericardium. $^{3,5,6,15}$

A reduction in the "bellows" action of LV contraction on the $\mathrm{RV}^{25}$ also appears to be implicated in the 


\begin{tabular}{|c|c|c|c|c|c|c|c|}
\hline \multirow[b]{3}{*}{$\begin{array}{c}L_{e d} \\
(\mathrm{~cm})\end{array}$} & \multicolumn{3}{|c|}{$R V$} & \multicolumn{4}{|c|}{$R V R S W-L_{e d}$ relationship } \\
\hline & \multirow[b]{2}{*}{$\begin{array}{l}\Delta L \\
(\%)\end{array}$} & \multirow[b]{2}{*}{$\begin{array}{c}M E P \\
(m m H g)\end{array}$} & \multirow[b]{2}{*}{$\begin{array}{c}R S W \\
\left(\mathrm{erg} \cdot 10^{3} \cdot \mathrm{cm}^{-2}\right)\end{array}$} & \multicolumn{2}{|c|}{ Control } & \multicolumn{2}{|c|}{ Aortic constriction } \\
\hline & & & & $\begin{array}{c}\text { Slope } \\
\left(\mathrm{erg} \cdot 10^{3} \cdot \mathrm{cm}^{-2}\right)\end{array}$ & $\begin{array}{c}x \text {-Intercept } \\
(\mathrm{mm})\end{array}$ & $\begin{array}{c}\text { Slope } \\
\left(\mathrm{erg} \cdot 10^{3} \cdot \mathrm{cm}^{-2}\right)\end{array}$ & $\begin{array}{l}x \text {-Intercept } \\
(\mathrm{mm})\end{array}$ \\
\hline $9.7 \pm 4.0$ & $7.6 \pm 4.0$ & $36 \pm 4$ & $2.8 \pm 2.0$ & $31.4 \pm 13.6$ & $8.8 \pm 3.9$ & $29.6 \pm 15.5$ & $8.7 \pm 3.9$ \\
\hline $9.7 \pm 4.0$ & $7.3 \pm 3.9$ & $38 \pm 7$ & $3.4 \pm 2.3$ & $37.4 \pm 16.6$ & $8.8 \pm 3.8$ & $32.4 \pm 10.4$ & $8.9 \pm 3.7$ \\
\hline
\end{tabular}

reduction in RV stroke work with increased LV afterload. Increased LV afterload impeded shortening of the anteroposterior and base-apex cardiac dimensions (Table I). It is via its effects on shortening of these dimensions that LV contraction exerts its "bellows" action on the RV. ${ }^{25}$ We estimated the contribution of this mechanism to the reduction in RV stroke work by computing the stroke work that would have been generated if shortening of the RV septal-free wall dimension had remained unaltered by the increase in LV afterload (Table III); thus, the reduction in RV stroke work would have been due entirely to reduced shortening of the anteroposterior and base-apex dimensions. This analysis indicated that $34 \%$ of the reduction in RV stroke work, on average, could be accounted for by reduced RV septal-free wall shortening, suggesting that the "bellows" mechanism might account for the remaining two thirds of the reduction in RV stroke work.

The ellipsoidal shell subtraction model used to determine RV volume in this study has been validated previously under much more extreme conditions of altered $\mathrm{RV}$ and LV geometry than were encountered in the present study. ${ }^{17}$ In that previous study,,${ }^{17}$ the volumes of intracavitary RV and LV balloons were varied independently over the range from 0 to $60 \mathrm{~mL}$. Despite the gross distortions of biventricular geometry and interventricular septal position produced by this procedure, the estimates of RV volume by the ellipsoidal shell subtraction method were shown to be independent of LV volume changes.

The pericardium was deliberately left open in our experiments to avoid an unphysiologic degree of pericardial constraint due to surgical closure and subsequent healing during the 7 to 10 days before data collection. The normal intact pericardium enhances diastolic $^{3,5,6,15}$ and, to a lesser extent, systolic ventricular interaction. ${ }^{15}$ Because we observed a direct ventricular interactive effect of increased LV afterload on RV work output with the pericardium open, it seems likely that this interaction would be greater, if anything, with the pericardium intact.

The data presented in this report provide the first experimental evidence of a direct, negative systolic ventricular interaction. The increment in LV mean ejection pressure induced by aortic constriction was quite modest $(25 \% \pm 14 \%)$, yet RV stroke work fell by $20 \%$ $\pm 13 \%$ for any given end-diastolic volume. This marked sensitivity of RV stroke work to LV afterload contrasts with the fact that proportionately larger increments in RV afterload (a $71 \% \pm 26 \%$ increase in RV mean ejection pressure) caused no reduction in RV stroke work for any given end-diastolic volume. ${ }^{16}$ Thus, RV stroke work is more sensitive to LV afterload than to RV afterload, reflecting the normal dependence of RV work output on LV contraction.

\section{REFERENCES}

1. Taylor RR, Covell JW, Sonnenblick EH, Ross J Jr. Dependence of ventricular distensibility on filling of the opposite ventricle. Am J Physiol 1967;213:711-8.

2. Laks MM, Garner D, Swan HJC. Volumes and compliances measured simultaneously in the right and left ventricles of the dog. Circ Res 1967;20:565-9.

3. Elzinga G, van Grondelle R, Westerhof N, van den Bos GC. Ventricular interference. Am J Physiol 1974;226:941-7.

4. Santamore WP, Lynch JR, Meier G, Heckman J, Bove AA. Myocardial interaction between the ventricles. J Appl Physiol 1976;41:362-8.

5. Janicki JS, Weber KT. The pericardium and ventricular interaction, distensibility, and function. Am J Physiol 1980;238:H494503.

6. Glantz SA, Misbach GA, Moores WY, Mathey DG, Leveken J, Stowe DF, et al. The pericardium substantially affects the left ventricular diastolic pressure-volume relationship of the dog. Circ Res 1978;42:433-41.

7. Bove AA, Santamore WP. Ventricular interdependence. Prog Cardiovasc Dis 1981;23:365-88.

8. Elbeery JR, Owen CH, Savitt MA, Davis JW, Feneley MP, Rankin SJ, et al. Effects of the left ventricular assist device on right ventricular function. $\mathrm{J}$ Thorac Cardiovasc Surg 1990;99:809-16.

9. Donald DE, Essex HE. Pressure studies after inactivation of the 
major portion of the canine right ventricle. Am J Physiol 1954; 176:155-61.

10. Sawatani S, Mandell C, Kusaba E. Ventricular performance following ablation and prosthetic replacement of right ventricular myocardium. Trans Am Soc Artif Intern Organs 1974;20:629-36.

11. Seki S, Ohba O, Tanizaki M, Takahadshi S, Teramoto S, Sunada T. Construction of a new right ventricle on the epicardium: a possible correction for underdevelopment of the right ventricle. J Thorac Cardiovasc Surg 1975;70:330-7.

12. Weber KT, Janicki JS, Shroff S, Fishman AP. Contractile mechanics and interaction of the right and left ventricles. Am J Cardiol 1981;47:686-95.

13. Feneley MP, Gavaghan TP, Baron DW, Branson JA, Roy PR, Morgan JJ. Contributions of left ventricular contraction to the generation of right ventricular systolic pressure in the human heart. Circulation 1985;71:473-80.

14. Feneley MP, Olsen CO, Glower DD, Rankin JS. Effect of acutely increased right ventricular afterload on work output from the left ventricle in conscious dogs: systolic ventricular interaction. Circ Res 1989;65:135-45.

15. Slinker BR, Glantz SA. End-systolic and end-diastolic ventricular interaction. Am J Physiol 1986;251:H1062-75.

16. Karunanithi MK, Michniewicz J, Copeland SE, Feneley MP. Right ventricular preload recruitable stroke work, end-systolic pressure-volume, and $\mathrm{dP} / \mathrm{dtmax}$-end-diastolic volume relations compared as indexes of right ventricular contractile performance in conscious dogs. Circ Res 1992;70:1169-79.

17. Feneley MP, Elbeery JR, Gaynor JW, Gall SA, Davis JW, Rankin JS. Ellipsoidal shell subtraction model of right ventricular volume: comparison with regional free wall dimensions as indexes of right ventricular function. Circ Res 1990;67:1427-36.

18. Monroe RG, Gamble WJ, LaFarge WJ, Kumar AE, Stark J, Sanders GL, et al. The Anrep effect reconsidered. J Clin Invest 1972;51:2573-83.

19. Glower DD, Spratt JA, Snow ND, Kabas JS, Davis JW, Olsen $\mathrm{CO}$, et al. Linearity of the Frank-Starling relationship in the intact heart: the concept of preload recruitable stroke work. Circulation 1985;71:994-1009.
20. Karunanithi MK, Young JA, Kalnins W, Kestevan S, Feneley MP. Response of the intact canine left ventricle to increased afterload and increased coronary perfusion pressure in the presence of coronary flow autoregulation. Circulation 1999;100:1562-8.

21. Feneley MP, Gavaghan T. Paradoxical and pseudoparadoxical interventricular septal motion in patients with right ventricular volume overload. Circulation 1986;74:230-8.

22. King ME, Braun H, Goldblatt A, Liberthson R, Weyman AE. Interventricular septal configuration as a predictor of right ventricular systolic hypertension in children: a cross sectional echocardiographic study. Circulation 1983;68:68-75.

23. Schimada R, Takeshita A, Nakamura M. Non-invasive assessment of right ventricular systolic pressure in atrial septal defect: analysis of the end-systolic configuration of the ventricular septum by two-dimensional echocardiography. Am J Cardiol 1984;53:1117-23.

24. Olsen CO, Tyson GS, Maier GW, Spratt JA, Davis JW, Rankin JS. Dynamic ventricular interaction in the conscious dog. Circ Res 1983;52:85-104.

25. Rushmer RF. Cardiovascular dynamics. Philadelphia: WB Saunders; p. 1970.

26. Streeter DD Jr. Gross morphology and fiber geometry of the heart. In: Handbook of physiology. ed 2, section 2. Bethesda: American Physiology Society; 1979. p. 66-8.

27. Langille BL, Jones DR. In: Berne RM, editor. Mechanical interactions between the ventricles during systole. Can J Physiol Pharmacol 1977;55:373-82.

28. Maughan WL, Kallman CH, Shoukas A. The effect of right ventricular filling on the pressure-volume relationship of the ejecting canine left ventricle. Circ Res 1981;49:382-8.

29. Santamore WP, Lynch PR, Heckman JL, Bove AA, Meier GD. Left ventricular effects on right ventricular developed pressure. J Appl Physiol 1976;41:925-30.

30. Yamaguchi S, Tsuiki K, Miyawaki H, Tamada Y, Ohta I, Sukekawa H, et al. Effect of left ventricular volume on right ventricular end-systolic pressure-volume relation: resetting of regional preload in right ventricular free wall. Circ Res 1989;65:623-31

\section{Authoritative}

The Journal of Thoracic and Cardiovascular Surgery is the most frequently cited thoracic/cardiovascular surgery journal in the Science Citation Index. An article in JTCVS is sited on average almost twice as often as those in the closest cardiothoracic journal. 